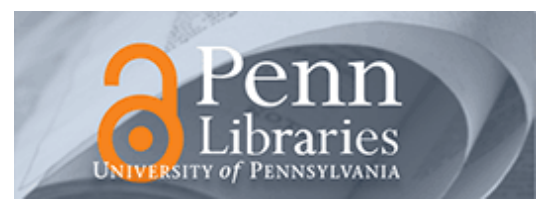

University of Pennsylvania

ScholarlyCommons

Marketing Papers

Wharton Faculty Research

6-1974

\title{
Consumer Research and the Evaluation of Information Disclosure Requirements: The Case of Truth in Lending
}

George S. Day

University of Pennsylvania

William K. Brandt

Follow this and additional works at: https://repository.upenn.edu/marketing_papers

Part of the Business Analytics Commons, Business Intelligence Commons, Finance and Financial Management Commons, Marketing Commons, and the Statistics and Probability Commons

\section{Recommended Citation}

Day, G. S., \& Brandt, W. K. (1974). Consumer Research and the Evaluation of Information Disclosure Requirements: The Case of Truth in Lending. Journal of Consumer Research, 1 (1), 21-32.

http://dx.doi.org/10.1086/208578

This paper is posted at ScholarlyCommons. https://repository.upenn.edu/marketing_papers/247

For more information, please contact repository@pobox.upenn.edu. 


\title{
Consumer Research and the Evaluation of Information Disclosure Requirements: The Case of Truth in Lending
}

\author{
Abstract \\ This article evaluates the impact of Truth in Lending (TIL) disclosures on consumer search and credit \\ usage behavior, and how the effects vary by market segment. Consumer behavior concepts were used to \\ guide the development of a comprehensive model of the consumer credit decision process, which \\ specified the intervening effects of TIL and the situational constraints which tended to limit the use of TIL \\ information.

\section{Disciplines} \\ Business | Business Analytics | Business Intelligence | Finance and Financial Management | Marketing | \\ Statistics and Probability
}


Graduate School of Business

STANFORD UNIVERSITY

Research Paper No. 166

CONSUMER RESEARCH CONTRIBUTIONS TO

THE EVALUATION OF PUBLIC POLICY:

THE CASE OF TRUTH IN LENDING

\author{
George S. Day \\ and
}

William K. Brandt

July 1973

* Associate Professor of Marketing, Stanford University and Assistant Professor of Marketing, Columbia University. The authors are indebted to the National Commission on Consumer Finance for their support of this study and to Professors Robert Johns on of Purdue University and Robert P. Shay of Columbia University for their helpful comments during all stages of the research. The contributions of the early work by Murray Silverman [27], and the follow-up study by Terry Deutscher [8], to the overall research program are also gratefully acknowledged. 
INTRODUCTI ON

\begin{abstract}
This paper explores two converging trends of potential interest to consumer researchers. The first is the burgeoning area of evaluation research, and the second is the growing interest of legislators and regulators in information disclosure as a means of assisting or protecting consumers. 1 One of the points of convergence is an evaluation of the impact of Truth in Lending (TIL) legislation on consumer behavior conducted by the authors for the National Commission on Consumer Finance. The primary objective of this paper is to demonstrate how concepts developed from consumer behavior theory were combined with the methodology of evaluation research to assess the result of this public policy. The paper will also summarize the research results, but a more complete report can be found elsewhere [7]. From this example we hope to stimulate greater appreciation for the nature and problems of evaluation research in general [and of the evaluation of information disclosure regulation in particular].
\end{abstract}


THE NATURE OF EVALUATION RESEARCH

All evaluations are designed to judge the results of programs or activities, and provide a basis for subsequent decisions about the progxam $[28,30]$. While the research can include an on-site monitoring or process evaluation which considers the quality and use of inputs (how well is the project being implemented), common usage limits the focus to program outcomes. Virtually all social programs are subject to some type of formal evaluation of outcomes. ${ }^{2}$ Frequently the enabling legislation will make an evaluation mandatory. Until recently this has not been the case with most legislation or regulation in the consumer protection area. This is largely because such initiatives as unit pricing and nutritional labeling do not require significant annual funding and do not have a fixed termination date.

The evaluator is faced with the same basic question in virtually all cases: to what extent is the program achieving its goals? The amount of guidance from such a seemingly straight-forward question is often illusory. Program goals are frequently hazy and ill-defined (for example, the objectives of TIL must be inferred from statements made by proponents during the hearings on the bi11), and there may be substantial unforeseen consequences that have to be considered. The focus on goals also ignores the need of the decision-maker to understand why the program is succeeding or failing. Since programs are seldom evaluated with a go/no go decision in mind [30, page 17], it is often more important that the evaluation contribute to the improvement of the program by identifying successful components and barriers to the realization of goals. ${ }^{3}$

Due to the nature of the basic evaluation question there is a clear hierarchy of research designs: 
Most desirable design $=0$ classical Fisherian before-after experimental design with controls (preferably with factorial arrangements)

- quasi-experiments with impure control groups, i.e., training program trainees compared with their unemployed friends

- correlational designs in which statistical controls are used

- qualitative audits by outside observers

Least desirable design $=0$ narrative reports by project and program adminis trators

Circumstances beyond the researcher's control frequently limit the choice of designs. For example, even where before-after studies are feasible, nationwide implementation of a program (e.g. Truth in Lending disclosure) may affect everyone eligible or interested and thereby eliminate the possibility for random assignment to a control group. Randomization itself may create problems if practitioners want to assign subjects to "treatment" on the basis of providing the service most suitable to their needs (e.g., selecting students with a greater propensity to learn a particular ski11), or if the randomizing process is so conspicious that it produces a Hawthorne effect [30, page 63]. Furthermore, if the effects occur only after long periods of exposure, the controlled experiment may require too much time [23, page 48].

Because of the numerous problems encountered in designing a controlled experiment, evaluation researchers are normally forced to compromise and accept a less desirable design. Instead of attempting to control for all rival hypotheses, a quasi-experimental design is created and special controls are added to account for specific rival explanations [2, page 60]. Sometimes even the quasi-experimental approach is not feasible and the evaluator must resort to a non-experimental or correlational design, 
such as: (a) a before-after study of a single program, or (b) an afteronly study of participants and non-random controls. Although these "soft" designs cannot control for rival explanations of effects, they can be used to identify programs and projects that are ineffective. If a "treatment" or program demonstrates no effect on the dependent variable (s), when evaluated by these designs, it will probably not show any effects when evaluated with more rigorous procedures [23, page 47].4

The research design will be further guided by the theoretical assumptions and expectations underlying the program's development and introduction. Basically the researcher must identify the implicit or explicit notions as to the process in which program inputs will lead first to certain intervening conditions or outcomes and then to the desired ultimate outcomes. The long time lags for most social programs (e.g. the long-term effects of Head Start) often require the researcher to develop a hierarchy of intervening and ultimate objectives and focus on the evaluation of the former. This is directly analogous to setting product advertising objectives that require the achievement of changes in awareness, knowledge and attitudes on the grounds that these are preconditions to changes in purchasing behavior [5, 17]. Frequently the intervening goals of programs become ends in themselves, and absorb the largest amount of program activity [28, page 55].

To the extent that the evaluation procedures can test the postulated linkages between the intervening conditions and the desired outcomes the researcher can determine whether the program activities are properly designed and directed. It may be that the theory is incorrect or that unforeseen circumstances are limiting the impact of the program. The diagnostic 
gains from incorporating intermediate outcomes into an evaluation was a major consideration in the design of the TIL study. In the next sections we describe the evaluation problem, the role of consumer behavior theory in specifying the intervening and ultimate outcomes, the research design used and a summary of the results.

THE GOALS OF TRUTH IN LENDING

Truth in Lending (TIL) was signed into law in May 1968 as Title 1 of the Consumer Credit Protection Act and became effective on July 1, 1969. The legislation essentially required all sources of consumer credit to disclose the annual percentage rate (APR) and the dollar finance charges for any transaction involving consumer credit. The APR (or interest rate) information was not previously available to consumers on a uniform basis: a veriety of methods such as monthly, discount and add-on rates were used-all of which stated rates considerably below the APR [20, page 169]. Information stating the dollar finance charges on credit transactions had sometimes been provided before TIL, but the law standardized this disclosure.

The disclosure of credit terms was expected to stimulate substantive changes in the behavior of consumers and credit sources. First, the comparable APR information would help consumers to shop for credit on a "price" basis just as they might shop for a product on this basis. Second, the level of the APR or dollar finance charges might induce some consumers to pay cash instead of credit, to choose less expensive models or products, to reduce the credit charges, or to postpone the purchase altogether. Finally, price competition among credit sources might become keener because 
of the increased consumer knowledge about credit costs. Other objectives such as economic stabilization were also attributed to TIL, but the primary goals focused on comparison shopping, judicious use of credit, and price competition among credit sources. 5

This research focuses on the first two goals and attempts to measure the influence of disclosure on actual purchase behavior-namely, the effects on comparison shopping and how credit was actually used. The third goal dealing with price competition for credlt requires a completely different research methodology and was therefore not covered in the study.

The earlier distinction between intervening and ultimate outcomes is helpful in clarifying the relations among the goals. In effect, the first intervening condition or outcome is an improvement in consumer knowledge about credit terms. This leads to changes in consumer search and creditusing behavior which may be considered as both intervening and ultimate outcomes; they may be a precondition to the stimulation of competition among credit sources but ultimate in the sense of encouraging more judicious credit usage.

\section{CHOOSING A RESEARCH DESTGN}

Because TIL was implemented nationwide on July 1, 1969 and funds for evaluation were not available until a year later, there were no opportunities for control groups or before-after studies. These realities forced us to rely on statistical associations between consumer knowledge and behavior after TIL was implemented. 
Fortunately several circumstances made this design more acceptable. First, monitoring by the Federal Trade Commission revealed that credit sources of all types were complying with the disclosure requirements. This eliminated the rival hypothes is that TIL disclosure had no effect on behavior because it was never provided.

Second, the Federal Reserve Board had conducted a large national survey ( $N=5000$ households) in May 1969 (one month before TIL) to measure consumer knowledge of credit rates and was planning a follow-up survey in October 1970. This before-after design would indicate the extent of change in consumer knowledge during the intervening seventeen months. Furthermore, there were strong arguments, based on a combination of limited time series evidence and the absence of rival hypotheses, for attributing improvements in knowledge to TIL disclosure. 6

An additional influence on the design was the possibility of a continuing improvement in knowledge beyond the October 1970 Federal Reserve Board survey. The question was whether the level of knowledge would continue to improve as more consumers experienced several credit transactions in which TIL disclosures were made, or conversely would decline as disclosure became a familiar part of the transaction and publicity about TIL was discontinued [31]. 7 Since it was essential that our survey of the impact of TIL on behavior be conducted at the same time as the follow-up Federal Reserve Board survey of knowledge, (so the two projects would be complementary) it was decided to conduct a reinterview in. June 1971 to measure further changes in knowledge as well as to gain further insights into the determinants of change. 
Finally, one of the principal objectives of this evaluation was to evaluate the effects of TIL disclosure within various segments of consumers. In particular the research was expected to help resolve the controversy over whether the benefits of TIL disclosure would extend to low-income and minority consumers. One class of arguments dismissed informational legislation, in toto, on the grounds that low income and minority consumers lacked the characteristics of the model consumer implicitly assumed by the legislation, including: (2) a belief in comparative shopping, and an ability and willingness to shop outside the local neighborhood, (b) an ability to pick out the "best buy," and (c) freedom to engage in comparative shopping [24]. Other critics held that lack of information was not the problem. Instead, "there is much evidence that some consumers in the poverty areas understand very wel1 that they are being bilked by high cash prices and high finance charges; but they also know that merchants or credit agencies with lower charges are not going to extend credit to them [15]." Furthermore these consumers are "rationed" in the sense that they cannot obtain as much debt as they would like because of the rates being charged [13]. Their reaction to these conditions is to seek credit terms with the lowest monthly payment and the longest maturity. To the extent that the decision criteria and behavior are different for low-income and minority consumers, the role played by TIL disclosure may also be quite different and less important.

Considering both the natural limitations on the research design and the objectives for the study, a correlational design with statistical controls was chosen to test the following hypotheses: (1) that TIL disclosure had no 
substantial effect on information search and comparison shopping for goods or credit; (2) TIL disclosure had no substantial effect on purchase behavior to postpone purchases or to use cash instead of credit; and (3) the relative impact TIL disclosure on low-income and minority consumer behavior would be less than for other segments. The first two hypotheses relate the level of consumer knowledge to actual purchase behavior whereas the third hypothesis focuses on the constraints which may limit TIL's potential impact for some consumer segments.

\section{THEORETICAL INPUTS TO THE DESIGN}

Consumer behavior theory contributed significantly to the basic design of the study. Key notions about consumer behavior and their supporting research were used to structure the overall design and to suggest hypotheses, variables to include and measurement procedures. Three of the more important models or concepts used were: the decision process model, the hierarchy of effects model, and the concept of attitude structure. The first suggests that most purchase decisions are the end result of a process that approximates the steps in a problem-solving paradigm (see figure below). This process is particularly applicable to the study of major expenditures on cars and household durables which were the focus of this study. The hierarchy of effects model postulates a series of cognitive steps through which a recipient of information proceeds prior to behavior, and the notion about attitude structure provides insights into the evaluative criteria used by consumers to make choice decisions. 
Virtually all decision-process models include the following steps, through which the consumer passes, and also provide for feed-back loops [11]. Although these models have served as the basis for extensive

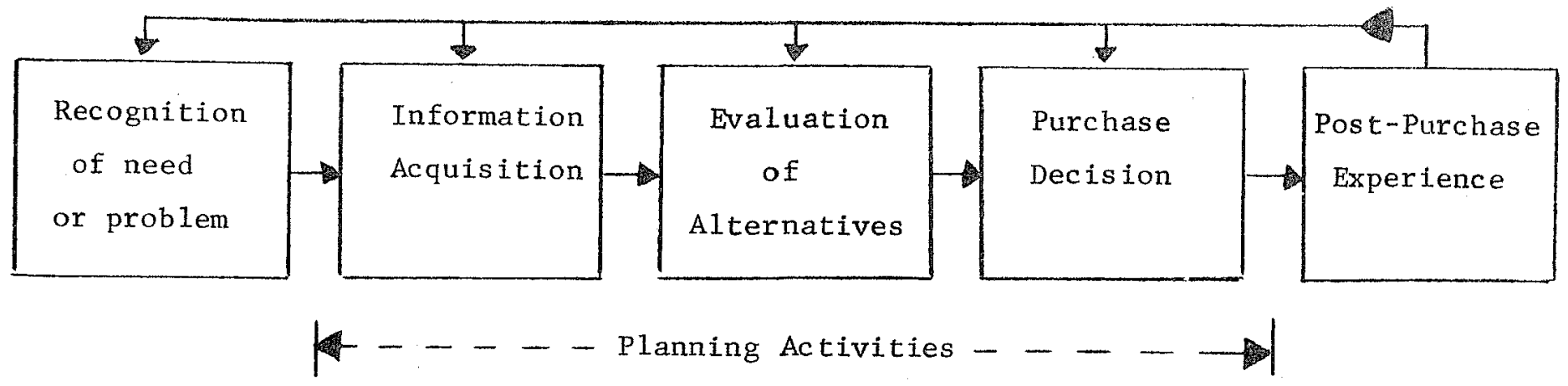

elaboration by consumer behavior theorists $[9,12,22]$, little is known about the relationships between the different stages. This made it difficult to determine the timing or sequencing of events where credit information might enter the decision process. More importantly, none of the models explicitly incorporated a second decision process dealing with the cash versus credit decision or the choice of a credit source.

Fortunately a previous study by Silverman provided considerable evidence on the nature of credit decisions and their relationship to such influences as the urgency of need, perceived credit availability and the choice of retailer or dealer. These results and the major elements of credit decisions are integrated into the overall decision process in Figure 1. The particular events shown are only appropriate to purchases of major household durables, automobiles and other substantial purchase decisions.

The decision process represented in Figure 1 deliberately highlights the credit-related decisions and implies that they play a pivotal role in the overall decision process. It should not be forgotten that a sequence of decisions is portrayed and that in reality credit decisions may be largely determined by the product-related decisions made earlier in the sequence. 
There are additional caveats to the interpretation of Figure 1 that are common to all behavioral process models, namely that the order of events may not apply to everyone and that individual stages can be skipped. A further limitation of this diagram is that it does not reflect changes in the role and importance of choice criteria as the decision process proceeds. For example, price may determine the set of brands and retailers to consider and may reappear later as an important influence if the credt charges are too onerous for the budget. A decision to purchase a cheaper brand or model, or forego an accessory is an alternative to postponing a purchase. Credit availability, to the extent that it is a real constraint, appears as a central element in the hypothesized sequence of decisions. It is shown. as influencing both the choice of retailer or dealer (in the event that the consumer cannot get credit elsewhere) and the likelihood that sales credit will be used to finance the purchase. (Sales credit can mean either using the dealer's charge or instalment loan plan or having the dealer to make credit arrangements with a bank or finance company on the buyer's beha1f.)

From Figure 1 we can also see that exposure to the information provided by TIL is hypothesized to have the same effects as a persuasive communication in the hierarchy of effects model [17]. That is, the most immediate and direct effect of the communication is to show the buyer the APR and dollar finance charges for a specific contract, 8 and also to improve the buyers general knowledge of prevailing rates and charges. This learning of credit terms occurs before the communication (the provisions of the contract) can move the buyer to a different state of attitude and behavior. The attitudinal components hypothesized to be influenced by TIL information are (a) the perceptions of the relative costs of alternative credit sources, and (b) the 
attitude toward the benefits versus costs of credit. ${ }^{9}$ Figure 1 shows that the consequences of these attitudinal changes, on the choices of a credit source and of cash versus credit or postponement, are first mediated by more general attitudes and environmental influences. A crucial question to evaluate is the degree to which these mediating factors, in the context of all other constraining decisions made previously, will overwhelm the immediate consequences of the TIL information.

IMPLEMENTING THE RESEARCH DESTGN

\section{Collecting the Data}

The data were obtained from personal interviews with 793 California heads of households in October 1970 (T1) and reinterviews with a random subsample of 196 households in July 1971 (T2). Six hundred and forty-one respondents in the initial survey were part of a probability sample whereby each family in the state theoretically had an equal chance of being interviewed. A separate probability sample of 142 black households were drawn from census tracts throughout the state with high concentrations of black households. The black sample supplements the statewide survey for purpose of more thorough study of the problems, attitudes, and behavior of black consumers. 10 It is inappropriate to combine the two samples to make generalizations about the California population, but where the focus is on differences between groups within the population, such as blacks and whites, the two samples can be joined without serious bias to the basic relationships. Because of the difficulties of interviewing migrants and extremely low income groups, there was a slight bias toward families with higher levels of education and income. In other respects the $\mathrm{T} 1$ sample was representative 
the population of California. A separate comparison of California households with those in other states suggested that the survey results could be cautiously generalized to the United States population as we11. ${ }^{11}$ California households were found to be somewhat younger, better educated and heavier credit users, but their attitudes toward credit and knowledge of credit terms before TIL were similar to the rest of the country. The reinterview (T2) subsample of 196 households was representative of the baseline sample with one exception. ${ }^{12}$ Because of the deliberate effort to reinterview respondents who had reported a major credit purchase prior to T1, the T2 subsample was biased toward households with greater credit experience. Analysis of the data in the reinterview survey, as well as experience with similar panel designs augmented with a control group, suggests that the reactive or conditioning effect of participation in the baseline survey on reinterview responses was negligible.

The T1 survey gathered extensive data about each respondent's knowledge and attitudes toward consumer credit and credit sources, history of credit usage, extent of experience with credit sources, assets, debts and problems in dealing with credit sources, and monthly credit payments, attitudes toward size of debt, plus a wide range of demographic and soceo-economic variables. If the household had purchased a car or major household durable costing more than one hundred dollars during the previous year, and additional set of questions was asked of the respondents involved in the purchase decision. These questions retraced the sequence and nature of decisions during the decision process following the framework in Figure 1. Details on elapsed time spent planning and shopping, sources of information, distances traveled, 
types of retailers or dealers considered, prior experience with the dealer, and the order and perceived difficulty of the major decisions were obtained. For items purchased on credit, additional questions captured the details of the credit transaction; these included ability to pay cash, sources of credit considered, types of information consulted, role of retailer or dealer, and transaction details such as size of downpayment, size of payments and payment schedule (by consulting the record of the contract if necessary). During the reinterview the questions on credit knowledge, attitudes and experience were repeated. If a major purchase had been made in the interim, the purchase process was retraced as in the first interview. The procedure of having the consumer reconstruct the events that led to the purchase decision was not entirely satisfactory. Chaffee and McLeod argue that, "Once having thought through a decision, the economic mind can be expected to forget the prior steps and retain only the decision itself" [3, page 404]. The seriousness of this assertion is difficult to appraise, for even less is known about this problem than of the related area of measurement errors in reports of consumer expenditures [21]. In order to minimize the recall problem only the most recent purchase was studied: analysis showed that 41 percent of the purchases were made within three months and 60 percent within five months of the interview. Because the purchase was one of the most significant expenditures by the household during the year, recall of specific events presented few problems. ${ }^{13}$ Other sources of response bias, including inflating the amount of search time in order to look good to the interviewer, were thought to be independent of the recall period. 14 


\section{MEASURING ACCURACY OF KNOWLEDGE}

Before the influence of TIL disclosure on behavior could be evaluated it was crucial to determine whether the respondent knew the dollar finance charges and APR on the sales credit or money borrowed to make the purchase. The problem was to determine whether the respondents estimate was, in fact, accurate. Since it proved difficult for the interviewers to view the credit statement or contract, it was decided to define "awareness zones" in terms of the maximum and minimum rates prevailing in California for different types of credit (for example, the minimums were 8 and 12 percent for cars and household durables, respectively, with a 30 percent maximum for both product classes). Although these zones empirically derived, it is clear they overstated the true level of consumer knowledge. 15

A major purpose of the T2 reinterview was to deternine whether the rate of improvement in APR knowledge would continue beyond October 1970 . Ideally this would have been based on a comparison of the knowledge of rates and charges for an actual purchase during both interviews. Because of sample size constraints the number of respondents who made a major credit purchase prior to the first interview (T1) and also in the ten months before the reinterview (T2) was too small for reliable comparisons. To overcome this problem the analysis relied on answers to a hypothetical question asked of a11 respondents at $\mathrm{T} 1$ and $\mathrm{T} 2$. Respondents were asked to estimate the total cost (principal plus finance charges) and the APR that they would pay for a $\$ 500$ color television set purchased on a one-year retail installment contract with equal monthly payments.

Although hypothetical questions can be criticized because they are not based on actual experience, they have several notable advantages. First, knowledge measures $c$ an be obtained for non-purchasers as well as recent buyers 
of large items. Second, they avoid the problem of lack of knowledge of an actual purchase because the respondent's spouse was more involved in the financial details of the credit transaction. Third, hypothetical questions will be influenced by the same general impressions that are influential in the buyer's decisions to utilize credit and compare credit sources. Furthermore, comparisons among respondents and of the same respondent over time are facilitated by the elimination of the particular circumstances surrounding the individual purchases. In effect, by sacrificing an undertermined amount of external validity we have gained a more uniform measure .

Measuring General Knowledge About Credit Sources

Besides the APR being charge for an actual purchase, consumers also have a general idea (often called institutional

knowledge) about the relative cost and ease of borrowing from various sources of credit. As shown in Figure 1 these perceptions can play a key role in the eventual selection of a retailer or other credit source. In this study consumer perceptions about major credit sources were measured in three ways: an assessment of relative APR's of various sources, an evaluation of the perceived difficulty to borrow from various sources, and judgments of the degree of similarity or dissimilarity of the sources.

The first two procedures were relatively straight forward. The second measure simply asked respondents to estimate how difficult it would be for them to borrow or obtain credit from five different types of credit sources. For the former measure respondents were asked to judge whether the rates charged by each of nine credit sources were higher than average, about average, or 
lower than average. ${ }^{16}$ Estimates of actual rates were not requested on the grounds that most respondents were probably unable to make such specific estimates. This measure did not address the critical question of whether the perceived differences in APR's, e.g. between a bank instalment loan and a retail charge account, were important to the respondent or whether rates were even used to make comparisons among alternative credit sources. In order to elicit information on the attributes actually used to compare alternatives without employing a time consuming battery of scales a non-metric multidimensional scaling procedure was used to develop a perceptual map of the credit market [10] . AlI respondents were asked to judge the 36 pair-wise combinations of nine credit sources according to degree of similarity or dissimilarity. Once the dimensions of the perceptual space were determined from this input data [16], the presence of a relative cost dimension could be determined by seeing if a vector describing the rank order of sources obtained from the direct question on comparative rates could be fitted into the reduced space. Furthermore, if a relative cost dimension were identified, its importance vis-a-vis the other perceived dimensions of credit sources could be inferred from the degree of dispersion of the credit sources on the respective dimensions.

\section{SUMMARY OF RESULTS}

This section provides a brief overview of key findings selected to demonstrate both the benefits of incorporating into the evaluation the numerous variables needed to understand the decision process, and the constraints of a nonexperimental design. The complete results and supporting arguments 
can be found elsewhere [7].

Knowledge of Credit Terms

During the baseline (T1) survey there was a general tendency to uxderstate the interest rate (APR) on a recent purchase, and to overestimate the finance charges $^{17}$ (especially when compared with the prevailing interest rates in 1970 of 12 to 20 percent for car loans and 18 percent for household durable good loans and credit).

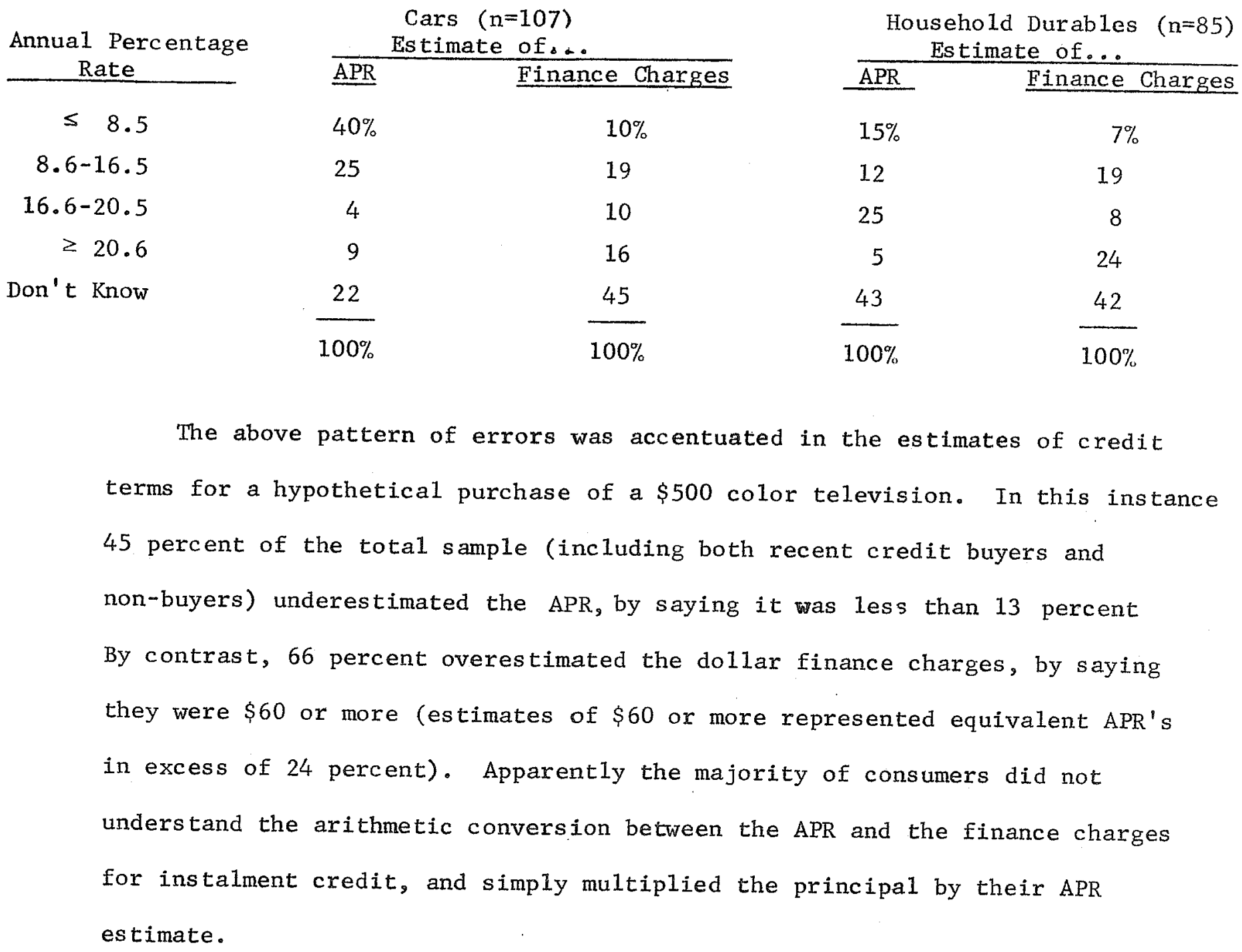




\section{Prospects for Change in APR Knowledge}

A cross-tabulation of the T1 and T2 estimates of APR for a hypothetical television purchase into the turn-over table below shows that the net changes revealed by the cross-sectional distributions serious $1 \mathrm{y}$ underestimate the total amount of change.

\begin{tabular}{|c|c|c|c|c|}
\hline & & & (JuIy 1971 & \\
\hline & & Correct & $\begin{array}{l}\text { Incorrect or } \\
\text { Don't Know }\end{array}$ & Tota1 \\
\hline & $\begin{array}{l}\text { Correct Estimate } \\
\text { Of APR }(13-24 \%)\end{array}$ & $22 \%$ & $\begin{array}{c}\text { forgetters } \\
15 \%\end{array}$ & $37 \%$ \\
\hline $\begin{array}{c}\text { T1 } \\
\text { (October 1970) }\end{array}$ & $\begin{array}{l}\text { Incorrect or } \\
\text { Don't know }\end{array}$ & $\begin{array}{c}\text { learners } \\
25 \%\end{array}$ & $38 \%$ & $63 \%$ \\
\hline & Total $(n=196)$ & $47 \%$ & $53 \%$ & $100 \%$ \\
\hline
\end{tabular}

If the rows of this turn-over table are standardized to sum to 1.0 , the results show that the transition probability of forgetting between $\mathrm{T} 1$ and $\mathrm{T} 2$ (0.40), given a correct estimate of APR at $\mathrm{T} 1$, was the same as the probability of learning between $\mathrm{T} 1$ and $\mathrm{T} 2(0.40)$, given an incorrect estimate. Consequently when 50 percent of the sample are able to give correct estimates, the number of forgetters equals the number of learners and no further improvement is possible. Since the proportion giving correct estimates was 47 percent at T2 the level of knowledge had effectively reached a ceiling or equilibrium. 18 In order to generalize from this forecast the transition probabilities must be the same for the rest of the population, and remain stable after $\mathrm{T} 2$. Both these assumptions can be supported (see footnote 11 and [8]).

\section{TIL Disclosure and Consumer Behavior}

(A) Comparison shopping: Three different approaches were used to determine the effect of APR knowledge on the extent of comparison shopping 
for credit. Each method by itself had notable deficiencies, but the composite result provided useful insights.

First, respondents were asked why they had chosen a particular dealer or retailer. From the open-ended responses it was possible to determine the relative influence of credit availability or better credit terms. Second, credit buyers were asked whether they had noticed any information. on the credit agreement or monthly statements related to the cost of borrowing, and if so whether the information was useful in any way.

Finally the relationship between accuracy of ÂPK knowledge and two types of search behavior 19 was estimated in the following credit usage situations:

Search Behavior Type of Credit Purchase

- Credit information search (1) cars

- Credit source search

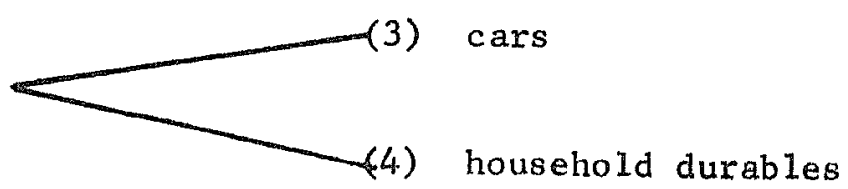

Regression analysis was used to hold constant the effects of education, age, sex of respondent, income, race, number of stores shopped and reliance on the dealer to make credit arrangements. The nu11 hypotheses that accurate APR knowledge had no incremental effect on behavior was rejected in equations (1) and (4); but even here the relationshins were not particularly strong in the sense that they greatly altered search behavior.

(B) Credit usage: Although the analysis did not explicitly study purchases which were postponed, an evaluation of the reasons for buying indicated between one-fourth and one-half of all purchases were not 
discretionary. Other indrect questions revealed that less than two percent of respondents would postpone purchases after learning the cost of credit.

The relationship between accurate APR knowledge and the decision to use cash instead of credit was evaluated again using regression analysis. The fact that no relationship whatsoever was observed when other possible influences were held constant suggests that TIL disclosure had not led to greater use of cash during the initial fifteen months of the law.

\section{Constraints on the Potential of Disclosure}

An evaluation of the constraints on the credit decision helps explain the relatively modest impact of TIL disclosure. In order to focus on the special problems of low income and minority buyers, the data base included both the representative and black samples. This affected only the proportions in the marginal distribution and not the relationships being studied.

(A) Importance of the Credit Decision. In the context of all the decisions involved in a major purchase on credit, the credit-related decisions assume little importance.

\begin{tabular}{lcc} 
Decision & $\begin{array}{c}\text { Most or second } \\
\text { most difficult } \\
\text { decision to make }\end{array}$ & $\begin{array}{c}\text { Least difficult } \\
\text { decision to make }\end{array}$ \\
\hline Amount to spend & $34 \%$ & $8 \%$ \\
Features or mode1 & 29 & 9 \\
Brand or make & 15 & 16 \\
Store or dealer & 9 & 30 \\
Cash or credit & 7 & 20 \\
Credit source & 6 & 17 \\
& $-100 \%$ & $-100 \%$ \\
& $(\mathrm{n}=291)$ & $(\mathrm{n}=291)$
\end{tabular}


The fact that the choice of store was one of the easiest decisions to make suggests that once the product-related decisions were made a11 but one of the store alternatives were eliminated for most of the buyers. Given the perceived ease of making the credit-related decisions it is not surprising that there was little credit search prior to the purchase.

(B) The Role of the Retailer. Retail credit, either charge accounts or instalment plans, was used by 38 percent of the buyers. Furthermore those who borrowed from banks or finance companies tended to turn over the credit source decision to the retailer: 86 percent did so for finance company loans and 56 percent for bank instalment loans. The net result was that 66 percent of all credit buyers relied on the retailer for credit, either through retail credit plans or dealer-arranged credit. 'Sharp differences were evident among segments however: 80 percent of blacks with income less than $\$ 7500$ used retail credit or dealer-arranged credit, compared with 55 percent of whites with income above $\$ 7500$, and 71 percent of whites with income below $\$ 7500$.

To some extent low income and minority buyers appeared to rely on the dealer because credit was unavailable elsewhere. Whereas 27 percent of low income blacks said they would have chosen another retailer had sufficient cash been available, only 7 percent of high income $(>\$ 7500)$ whites answered the same way. This question probably understates the constraint imposed by availability since some buyers who would not have chosen a different retailer if they could have paid cash might have been expressing their overall satisfaction with the retailer they had chosen.

There was no evidence that the reliance of low income and minority buyers retailer-arranged credit was strongly influenced by past experience, since 
the proportions of these segments who had made a previous credit purchase at the dealer or retailer (approximately 50 percent) were the same for other segments. Finally, low-income buyers and minorities were apparently not constrained in their choice of retailer because they lacked mobility and were forced to buy from neighborhood stores (as measured by the distance travelled to make the credit purchase); this result however may be peculiar to the sprawling nature of most California cities.

The remaining question is whether those who relied on retailer-arranged credit did so because they perceived that other sources of credit were either inaccessible or more expensive.

(C) Perception of Credit Sources. Respondents were asked how difficult it would be for them to obtain credit from major cash lending sources as we 11 as small stores (see Table 1). Judging from the small proportion of "don't know" responses, knowledge about accessibility to all but credit unions was widespread in the sample.

The differences between segments in perceived accessibility are helpful in explaining why low-income buyers seldom consider getting credit from sources other than retailers: only 15 percent of this group reported that it would be extremely or very difficult to use this source. Even small stores were rated as less accessible than retail instalment loans, presumably obtained from larger stores.

There was a realistic recognition among low-income and minority respondents that credit costs are higher for finance company and retail credit and somewhat lower for bank and credit union loans (Table 2). In fact, most consumers, regardless of race or income appeared to have a reasonable level of institutional knowledge regarding the relative costs of alternative credit sources. The major exception to this conclusion 
is the high level of don't know responses among the low income respondents for bank credit cards, bank single payment loans and credit unions because of lack of experience.

The results of the perceptual mapping study in Figure 2 suggest that relative cost was also the most important dimension in the comparison of credit sources. The vertical dimension corresponds closely to the rank order of perceived rates of credit sources in Table 2. The only exceptions are credit unions and single payment bank loans which switch their order, probably because of ignorance as to the relative costs of these sources. Only two dimensions were needed to obtain a very good fit to the data (with a stress of 0.010). The interpretation of the second, horizontal dimension is complicated by the location of single payment bank loans. Excluding this source, the dimension appears to represent a composite of convenience and average size of transaction. Using the criterion of relative dispersion of the sources along the dimension it appears that perceived cost is the most important dimension.

\section{CONCLUSIONS}

Evaluation research frequently requires finding answers to difficult questions concerning the achievements of programs relative to looselyspecified goals, with compromise designs. This evaluation of the impact of Truth in Lending is no exception to this characterization. The nation-wide implementation of this legislation eliminated from consideration the before-after experimental design which evaluators aspire to use.

This article describes the reinterview survey design used in this evaluation and the role of consumer behavior in strengthening the design. 
The major contribution of the theory was in structuring the relationships between the intervening and ultimate outcomes of the legislation, and suggesting hypotheses to test. For example, the existing theory and supporting research provided a rationale for embedding the credit decision process in the overall decision process. Once the principal relationships between the various decisions were identified it was possible to assess the various constraints on the potential of TIL disclosure. The lack of impact of TIL was found to be a logical consequence of choices (of cash versus credit or of credit source) that are perceived as relatively less difficult than product-related decisions and may be decided by default once a retailer or dealer is chosen. In a similar fashion models of the hierarchy of communication effect and attitude structure facilitated the analysis of the reasons for the high degree of reliance of consumers on retailers as sources of credit. 
FOOTNOTES

Recent initiatives in this area range from standards for warranties, to requirements for the provision of comparative performance, cost and ingredient information (including unit pricing, open dating, nutrient and octane labeling, Truth in Lending, Truth in Packaging and Truth in Life Insurance).

2

Well known evaluations are the Coleman et al study of equality of educational achievement [4], the New Jersey experiments on income maintenance plan [18] and the evaluation of the Head Start program [30, page 115].

3

The decision to institute a similar program elsewhere will require both kinds of information. The problem of whether to limit the evaluation to a determination of success or failure is analogous to the problem of deciding the proper role for a test market [26].

4

To put it another way, correlation does not imply causation, but the absence of a correlation can rule out causal hypotheses.

A summary of the major goals of TIL is presented in Chapter 10 of the Final report of the National Commission on Consumer Finance [20].

6

No new consumer credit legislation or hearings were publicized in this period and credit rates were reasonably stable. A limited amount of time series evidence suggested that rate awareness in the 1950's [19] remained at roughly the same low level as that measured during the first Federal Reserve study. Thus there was no trend or maturation effect underlying the following improvement in rate awareness reported by the Federal Reserve [25].

Type of Credit

Al1 Closed-end Credit (mortgages and instalment loans)

Retail Revolving Credit

Bank Credit Cards

Knowledge of APR for Specific Purchase

$\begin{array}{r}\text { May } 1969 \\ (n=5149) \\ \hline\end{array}$

$14.5 \%$

35.2

26.6
October 1970

$(n=5340)$

$38.3 \%$

55.5

63.4

A respondent was considered knowledgeable if he could estimate the APR on a recent purchase within the range of rates commonly paid in the marketplace. 
A related question was whether the change in awareness was attributable to the educational campaign or the information disclosed on the contract.

8

One of the problems in evaluating TIL is that the information is only shown on the credit contract, and a formal contract will probably not be prepared until the purchase is almost consummated. Thus the direction of influence shown in Figure 1 may be reversed, with knowledge of APR and charges on a specific contract coming only after the choice of credit source and credit plan.

9

Rather than ask whether it is generally a good or bad idea to buy on credit, it should be recognized that attitudes toward the use of credit are very situation specific; whereas it may be deemed appropriate to use credit to cover educational or medical expenses, a respondent may feel differently toward the use of credit to cover living expenses, pay for a vacation trip or buy a fur coat. These various situations can be approximately represented by a Guttman scale.

10

The California population includes about six percent blacks and seven percent chicanos. A probability sample of 800 households would be expected to include only about 50 families from each minority group.

11

This analysis employed a number of demographic, behavioral and attitudinal variables collected in a nationwide survey [14] by the Survey Research Center at the University of Michigan to compare 316 Californians with 2849 non-California households.

12

To achieve the 196 reinterviews a total sample of 347 with some record of credit usage was drawn. The completion rate was therefore 56.5, while no answers or extended vacations accounted for 8.9 percent, moves outside the neighborhood accounted for 14.7 percent, and refusals were 19.9 percent. Despite the attrition there was little difference between responders and non-responders on key demographic variables.

13

A subjective evaluation by the interviewer of each respondent's overa11 ability to answer the questions revealed that about 85 percent of respondents were confident and truthful about their answers. An intensive debriefing of each interviewer after all interviews were completed again indicated that nearly all respondents were able to recall the decision process with the guidance of directed questions and problems.

14

This problem would have also afflicted the alternative data collection procedure of using records of purchase to identify very recent purchasers. The virtual impossibility of obtaining a representative sample of purchasers using this procedure quickly eliminated it from consideration. 
15

The same concept was used to define accurate knowledge in the Federal Reserve study (see Footnote 6) except that no maximum levels were used in that study. The minimums were based on the results of a nationwide survey of APR's actually being paid by consumers for various types of borrowing.

16

The credit sources studied were finance companies, credit unions, store charge accounts, credit cards (both bank and other types), store instalment loans and bank instalment and single payment loans.

17

The estimate of finance charges on the purchase was combined with estimates of purchase price, trade-in value, down payment and number of monthly payments in order to compute an equivalent interest rate that could be compared to the direct estimate of APR.

18

The stable-state proportion of this or any other turn-over table can be estimated by treating the corresponding matrix of transition probabilities as a discrete - time Markov model [6].

19

Credit information search, conducted by 27 percent of credit buyers, referred to specific activities such as reading mailings or talking with friends about credit sources before the purchase, whereas credit source search, conducted by 20 percent, referred to actual shopping at various type of credit sources (although it did not include shopping for credit within one type of source). 


\section{REF ERENCES}

1. Brandt, William K., George S. Day, and Terry Deutscher, "The Effect of Disclosure on Consumer knowledge of Credit lerms: A Longitudinal Study," Working paper, Stanford Graduate School of Business, April 1973

2. Campbe11, Donald T. and Julian C. Stanley, Experimental and Quasi - experimental Designs for Research, Chicago: Rand McNa11y, 1963

3. Chaffee, Steven H. and Jack M. McLeod, "Consumer Decisions and Information Use," in Scott Ward and Thomas S. Robertson, Consumer Behavior: Theoretical Sources Englewood Cliffs, N.J., Prentice-Ha11, 1973, pps. 385-415

4. Coleman, James S. and Ernest Q. Campbe11, et al, Equality of Educational Opportunity, Washington, D.C.: U.S. Government Printing Office, 1966.

5. Day, George S., "Theories of Attitude Structure and Change," in Scott Ward and Thomas S. Robertson, Consumer Behavior: Theoretical Sources, Englewood Cliffs, N.J.; Prentice-Ha11, 1973, pps. $303-353$

6. Day, George S., "Using Attitude Change Measures to Evaluate New Product Introductions," Journal of Marketing Research, 7, November 1970 , pp 474-482

7. Day, George S. and William K. Brandt, A Study of Consumer Credit Decisions: Implications for Present and Prospective Legislation, National Commission on Consumer Finance, Report No. 2, Washingto, D.C.; U.S. Government Printing Office, 1973.

8. Deutscher, Terry, Credit Legis lation Two Years Out: Awareness Changes and Behavioral Effect of Differential Awareness Levels, National Commission on Consumer Finance, Report No. 3, Washington, D.C.; U.S. Government Printing Office, 1973

9. Enge1, James F., David T. Kollatt and Roger D. Blackwe11, Consumer Behavior New York: Holt, Rinehart and Winston, 1968

10. Green, Paul E. and Frank J. Carmone, Multidimensional Scaling and Related Techniques, Boston: A1lyn and Bacon, 1970

11. Hansen, Flemming, Consumer Choice Behavior: A Cognitive Theory, New York: Free Press, 1972

12. Howard, John A. and Jagdish Sheth, The Theory of Buyer Behavior, New York: John Wiley, 1969 
13. Juster, F. Thomas and Robert P. Shay, Consumer Sensitivity to Finance Rates: An Empirical and Analytical Investigation, New York: National Bureau of Economic Research, 1964

14. Katona, George, James N. Morgan, Jay Schmiedeskamp and John A. Sonquist, 1967 Survey of Consumer Finances, Ann Arbor: Survey Research Center, University of Michigan, 1968

15. Kripke, Homes, "Gesture and Reality in Consumer Credit Reform," New York University Law Review, 44 (March 1969), 1-52

16. Kruska1, Joseph B., "Multidimensional Scaling by Optimizing Goodness of Fit to a Nonmetric Hypothes is," Psychometrika, 29 (March 1964), $1-28$

17. Lavidge, Richard C. and Gary A. Steiner, "A Model For Predictive Measurements of Advertising Effectiveness," Journal of Marketing, 25 (October 1961), 59-62

18. David N. Kershaw, "Issues in Income Maintenance Experimentation," in Peter H. Rossi and Walter Williams, (editors) Evaluating Social Programs: Theory Practice and Politics, New York: Seminar Press, 1972

19. Mors, Wallace P., Consumer Sensitivity to Finance Rates: An Empirical and Analytical Investigation, New York: National Bureau of Economic Research, 1964

20. National Commission on Consumer Finance, Consumer Credit in the United States, Washington, D.C., U.S. Government Printing Office, 1973

21. Neter, John, "Measurement Errors in Reports of Consumer Expenditures," Journal of Marketing Research, 7, (February 1970); 11-26

22. Nicosia, Francesco M., Consumer Decision Processes: Marketing and Advertising Implications, Englewood Cliffs, N.J.; Prentic-Ha11, 1966

23. Rossi, Peter H., "Testing for Success and Failure in Social Action," in Peter H. Rossi and Walter Williams, (editors), Evaluating Social Programs: Theory, Practice and Politics, New York; Seminar Press, 1972

24. Schnapper, Eric, "Consumer Legislation and the Poor," The Yale Law Journal, 76 (1967), 745-768

25. Shay, Robert P。 and Milton W. Schober, Consumer Awareness of Annual Percentage Rates of Charge in Consumer Instalment Credit: Before and After Truth in Lending Became Effective, National Commission on Consumer Finance, Washington, D.C.: U.S. Government Printing Office, 1973 
26. Stanton, Frank, "What is Wrong With Test Marketing?" Journal of Marketing, 31 (Apri1 1967), 43-48

27. Silverman, Murray I., Awareness of Credit Costs: Its Role in the Decision Process of the Low-Income Negro Consumer, unpublished Ph.D. dissertation, Stanford University, January 1972

28. Suchman, Edward A., Evaluative Research; New York: Russell Sage, 1967

29. Ward, Roberta A., "The Consumer Credit Protection Act: An Analysis of Public Policy Formulation," Journal of Consumer Affairs, $196-211$

30. Weiss, Carol H., Evaluation Research: Methods of Assessing Program Effectiveness, Englewood Cliffs, N.J., Prentice-Ha11, 1972

31. Whitford, William C. "The Functions of Disclosure Regulation in Consumer Transactions," University of Wisconsin Law Review, (forthcoming, 1973)

32. Williams, Walter and John W. Evans, "The Politics of Evaluation: The Case of Head Start," Annals of the American Academy of Political and Social Science, 385 (September 1969), 118-132 
Firure

A CRVIDT DECISION URIENTEU VIEW OF THE CONSUMER UWCISION PROCESS

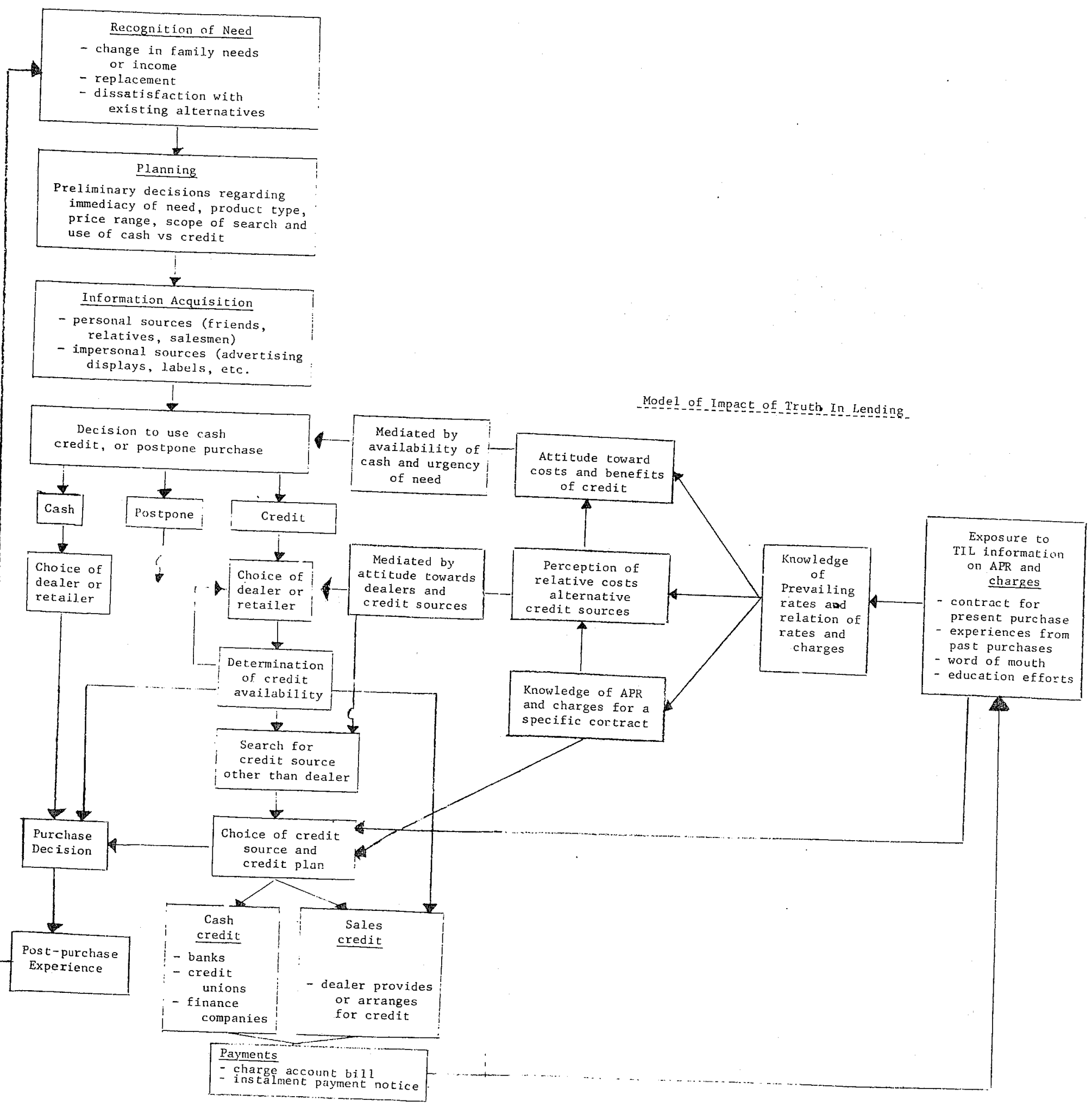


FIGURE 2

PERCEPTUAL MAP OF CREDIT MARKET

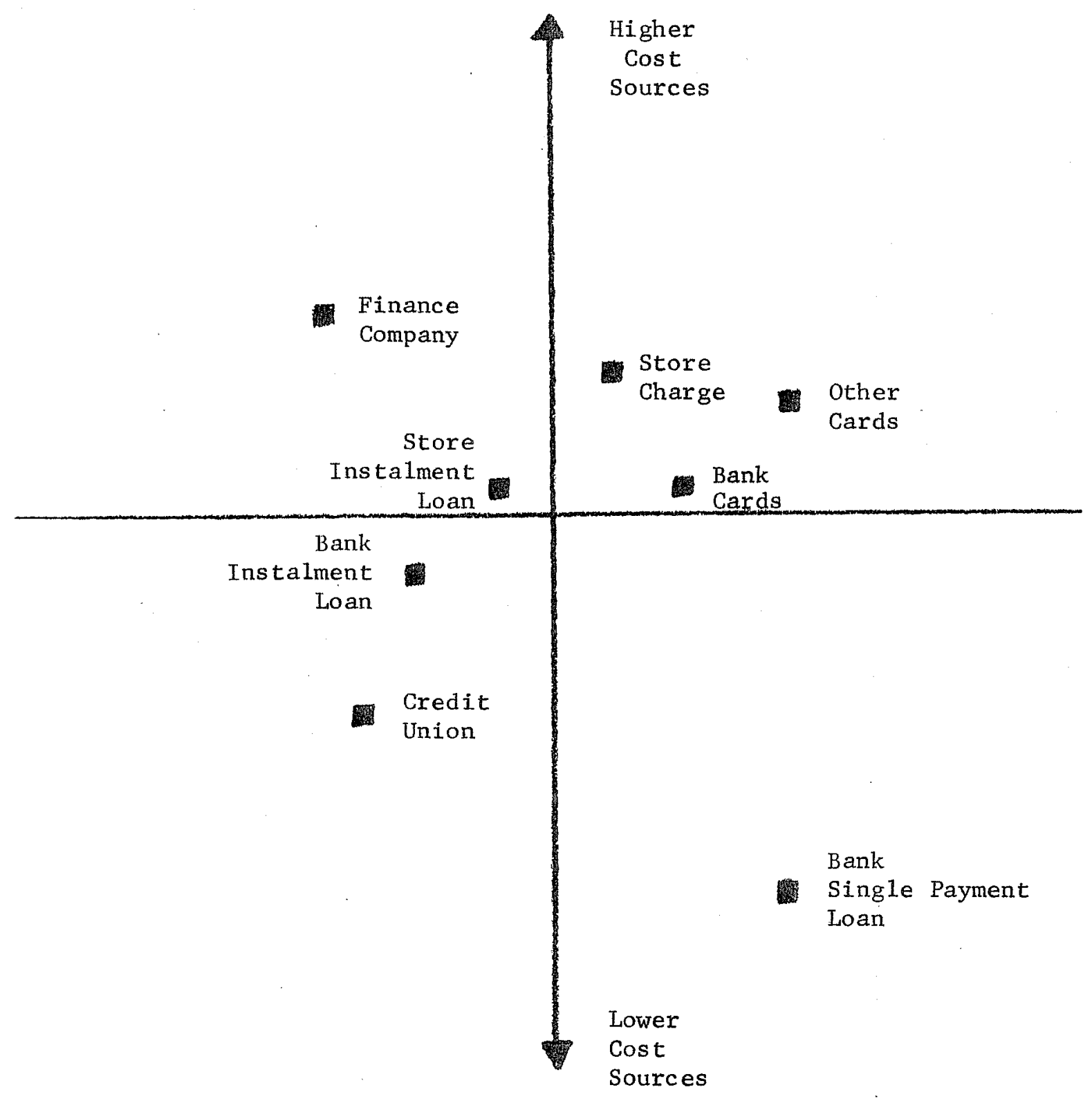


TABLE 1

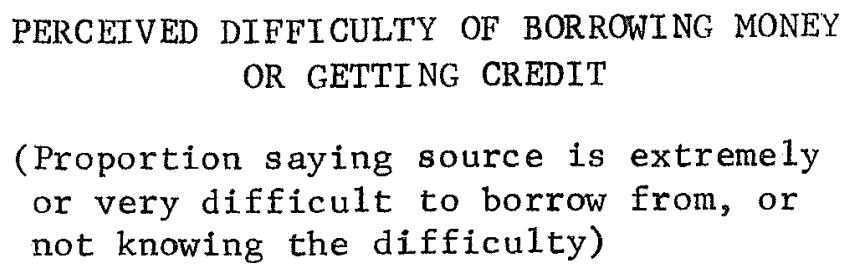

\section{Credit Source}

(A) Bank_Instalment_Loan

Extremely/very difficult Don't know

(B) Loan or Finance_Company

Extreme1y/very difficult Don't know

(C) Store_Instalment_Loan

Extremely/very difficult Don't know

(D) Sma 11 Storore

Extremely/very difficult

Don't know

(E) Credit Union

Extreme1y/very difficult Don't know

Number of Cases

\section{White}

Income Income

$\leq \$ 7500$
Minority

Income Income

$\leq \$ 7500 \quad \geq \$ 7500$
$25 \%$

$(8 \%)$

25

(14)

16

(8)

19

(13)

20

(35)

(146)

4

(4)

5
$(7)$

30

(5)

11

(5)

$23 \%$

$(7 \%)$

$(4 \%)$

$17 \%$

$(4 \%)$

Tota1 
TABLE 2

PERCEIVED ANNUAL PERCENTAGE RATES OF ALTERNATIVE CREDIT SOURCES

(Proportion saying that interest rate of credit source is above average or unable to estimate)

Credit Source

(A) Einance Company

Above average rates

Don't know

\begin{tabular}{lr}
\multicolumn{2}{c}{ White } \\
\hline Income & Income \\
$\leq \$ 7500$ & $\geq \$ 7500$ \\
\hline
\end{tabular}

$60 \%$

$(29 \%)$

(B) Retail Charge Account ${ }^{a}$
Above average rates

Don't know

(C) Bank Credit Card

Above average rates

Don't know

(D) Bank Instalment Loan

Above average rates

Don't know

(E) Bank Sing le Payment Loan

Above average rates

Don't know

8

(34)

23

(42)

24

(28)

38

(14)

26

(28)

33

(19)

$65 \%$

(15\%)

$68 \%$

$(20 \%)$

$(15 \%) \quad(30 \%)$

$$
\text { (19) }
$$

33

(20)

$\begin{array}{ccccc}16 & 14 & 17 & 15 & 16 \\ (26) & (13) & (29) & (17) & (18)\end{array}$

$\begin{array}{cccc}28 & 19 & 24 & 25 \\ (22) & (40) & (30) & (30)\end{array}$

(30)

$\geq \$ 7500$ Total

Minority

(F) Credit Union

Above average rates

Don't know

8
$(43)$

$(19)$

6
$(38)$

6
$(28)$

6

(28)

Number of Cases

(132)

(373)

(113)

(140)

(758)

a Distributions for retail charge accounts and retail instalment loans were nearly identical. 